\title{
CONTROLE DE MATERIAL PARTICULADO PROVENIENTE DA COGERAÇÃO DE ENERGIA DE UMA INDÚSTRIA SUCROALCOOLEIRA
}

\author{
A. S. DAMASCENO ${ }^{1}$, M. L. AGUIAR ${ }^{1}$ \\ ${ }^{1}$ Universidade Federal de São Carlos, Departamento de Engenharia Química \\ E-mail para contato: mlaguiar@ufscar.br
}

\begin{abstract}
RESUMO - Com o crescente aumento da produção de etanol no Brasil nas últimas décadas, faz-se necessário um tratamento dos efluentes da indústria sucroalcooleira cada vez mais eficiente. A combustão de bagaço em caldeiras é uma alternativa para o uso de um dos principais coprodutos gerados no processamento da cana-de-açúcar. No entanto, este processo de cogeração de energia produz um grande volume de material particulado poluente, que é fortemente prejudicial ao meio ambiente e à saúde humana e, portanto, sua emissão deve ser controlada, cumprindo as normas regulatórias de emissão de poluentes. Os separadores ciclônicos são equipamentos de tratamento de efluentes gasosos que apresentam baixo custo, simplicidade de implementação, facilidade de operação e manutenção. Para isso, o projeto teve como objetivo analisar o desempenho do equipamento operando com pulverizadores de água instalados na sua parte superior (ciclone úmido), com o intuito de otimizar a operação do equipamento na coleta de partículas respiráveis de material particulado. Os ensaios experimentais acompanharam as seguintes variáveis de processo: vazão de gás e água, vazão de material particulado, temperatura do sistema e tempo de coleta de material. Desta forma, o acionamento dos bicos injetores de água possibilitaram uma melhora de $5,02 \%$ na eficiência global de coleta de material particulado.
\end{abstract}

\section{INTRODUÇÃO}

A devastadora exploração do meio ambiente, durante as últimas décadas, tem gerado efeitos praticamente irreversíveis, cujas consequências acabam por comprometer o clima, a integridade de ecossistemas e, até mesmo, a existência de espécies. Dentro deste contexto, uma das maiores preocupações tem sido os efeitos nocivos que a exploração e a queima de combustíveis fósseis provocam para a humanidade (Aransiola et al., 2014).

À vista disso, tem-se, cada vez mais, chamado a atenção para a importância e valorização de energias renováveis, como os biocombustíveis, por exemplo. Por esta razão, nas últimas quatro décadas, tem sido estimuladas a produção e o consumo de etanol e, consequentemente, mostrou-se necessário um eficiente tratamento dos efluentes gerados.

A matéria-prima utilizada no Brasil para produção desse biocombustível é a cana-deaçúcar, em que um dos principais subprodutos gerados no processamento é o bagaço. A 
queima desta biomassa em caldeiras foi uma forma alternativa encontrada para direcionar o seu uso a fim de atender as demandas energéticas (térmicas, mecânicas e elétricas) das indústrias sucroalcooleiras.

No entanto, a combustão da biomassa produz uma grande quantidade de material particulado, cuja granulometria pode variar de nanômetros a centenas de micras, é composto basicamente por poeiras, fumaças e quaisquer outros sólidos e líquidos que se mantenham em suspensão no ar. As partículas que apresentam diâmetro inferior a $10 \mu \mathrm{m}$ são consideradas respiráveis e, quando liberadas na atmosfera, podem provocar sérios problemas de cunho ambiental e de saúde pública. Assim, é de extrema importância que as indústrias sucroalcooleiras controlem a emissão deste material poluente para a atmosfera, com o intuito de diminuir o impacto ambiental provocado por esse processo e de se adequar às normas regulatórias de controle ambiental, que se tornam cada vez mais rígidas.

De acordo com Almeida Filho (2008), os principais equipamentos utilizados para o tratamento de efluentes gasosos são: ciclones, lavadores de gás, filtros de manga, coletores gravitacionais e precipitadores eletrostáticos.

Os ciclones apresentam diversas vantagens, devido à baixa complexidade, com relação aos demais purificadores de gases, apresentando baixo custo operacional e facilidade de operação e manutenção. Contudo, a sua eficiência na separação de partículas inferiores a 5 $\mu \mathrm{m}$ não é muito elevada e, desta forma, devem ser estudadas alternativas de operação que melhorem a sua performance. Uma destas alternativas é a coleta do material particulado através da nebulização de líquido, introduzindo pulverizadores de água no seu interior e, assim, caracterizando o equipamento como um ciclone úmido.

Desta forma, o presente estudo teve como objetivos específicos a obtenção da eficiência de coleta de partículas respiráveis de carvão ativado, presentes em um fluxo de ar através de um ciclone úmido, com acionamento de bicos pulverizadores de água na parte superior do equipamento.

\section{MATERIAIS E MÉTODOS}

Esta seção irá retratar a preparação do material particulado para análise e todo o sistema experimental utilizado, bem como os métodos e procedimentos adotados durantes os ensaios experimentais realizados a seco e a úmido.

\subsection{Material Particulado}

O material particulado utilizado para análise foi o carvão ativado, visto que ele é um dos produtos originados pela combustão de matéria orgânica. Foi necessário caracterizar o material bruto, a fim de conhecer a distribuição dos tamanhos das partículas constituintes. Para isso, foi coletada uma amostra representativa para que fosse definida a distribuição granulométrica do material, realizada em triplicata pelo analisador de partículas Malvern Mastersize MicroPlus, MAF 5001. Assim, foi constatado que o carvão analisado apresentava diâmetro volumétrico de 103,86 $\mu \mathrm{m}$. 
Como a proposta deste estudo tinha como foco o aumento da eficiência de coleta de partículas respiráveis, foi necessário efetuar a cominuição do material disponível para que o seu diâmetro atingisse um valor inferior a $10 \mu \mathrm{m}$ e fosse, então, classificado como um material particulado inalável.

O processo de cominuição foi realizado em um moinho de bolas de formato cilíndrico (modelo DF51-322-055 - Moeller), cujo tambor apresentava capacidade de armazenamento de $0,0087 \mathrm{~m}^{3}$. O interior do tambor era preenchido até a metade do seu volume com esferas de diversos tamanhos e o restante dos espaços vazios foram ocupados com o material particulado. Para permitir a colisão e o atrito destas esferas com o material particulado, promovendo a sua cominuição, o tambor cilíndrico foi colocado em uma carcaça de ferro para melhorar a sua vedação e, horizontalmente, foi acoplado sobre um sistema de rotação máxima. Para que o material atingisse a granulometria desejada (inferior a $10 \mu \mathrm{m}$ ) foram necessárias quatro cominuições de quatro horas. A Figura 1 apresenta os valores de diâmetro médio das partículas submetidas a cada cominuição.

Figura 1 - Diâmetros médios das amostras a cada cominuição.

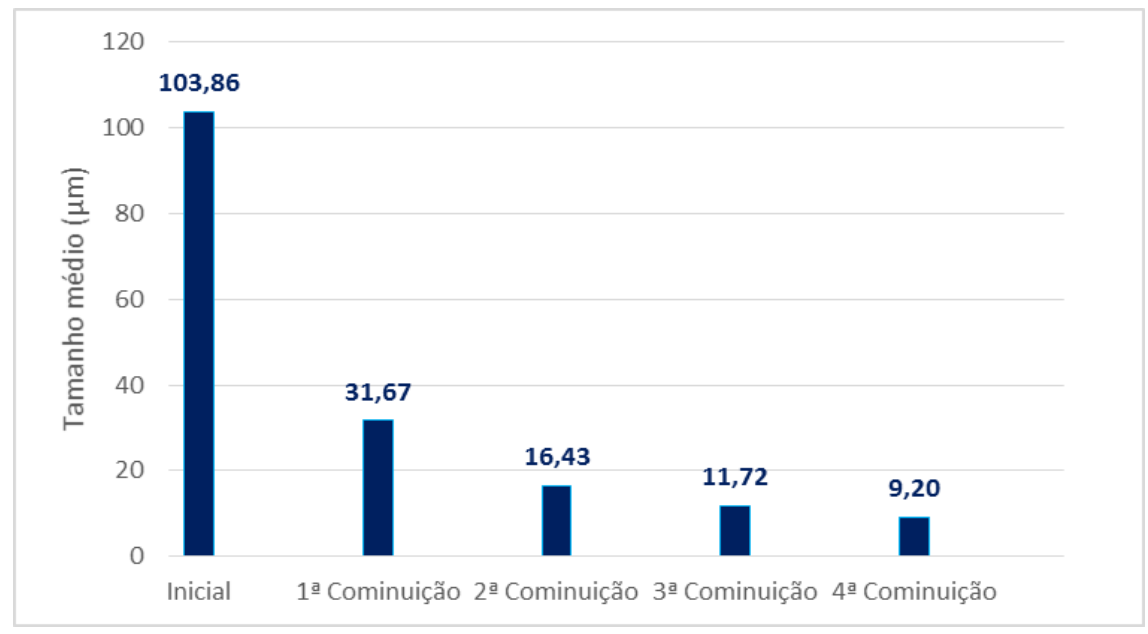

\subsection{Sistema Experimental}

O sistema experimental (Figura 2), situado no laboratório de controle ambiental do Departamento de Engenharia Química da Universidade Federal de São Carlos, foi utilizado para a determinação da eficiência do equipamento ciclone operando a seco e a úmido.

O sistema apresentado era composto pelos seguintes componentes: (1) soprador; (2) controlador de velocidade do prato giratório; (3) prato giratório de alimentação de material particulado; (4) aquecedor; (5) resistências elétricas; (6) variadores de voltagem; (7) sonda de amostragem do duto de saída; (8) sonda de amostragem do duto de entrada; (9) sistema de alimentação de água constituído por um reservatório, uma bomba de sucção e um rotâmetro para controle de vazão; (10) bomba de sucção de ar para amostragem de material; (11) ciclone; (12) caixa coletora de material particulado; (13) caixa de energia; (14) suporte manométrico; (15) duto de ar comprimido; (16) duto de água; e (17) estabilizador do soprador. 
Figura 2 - Ilustração do sistema experimental.

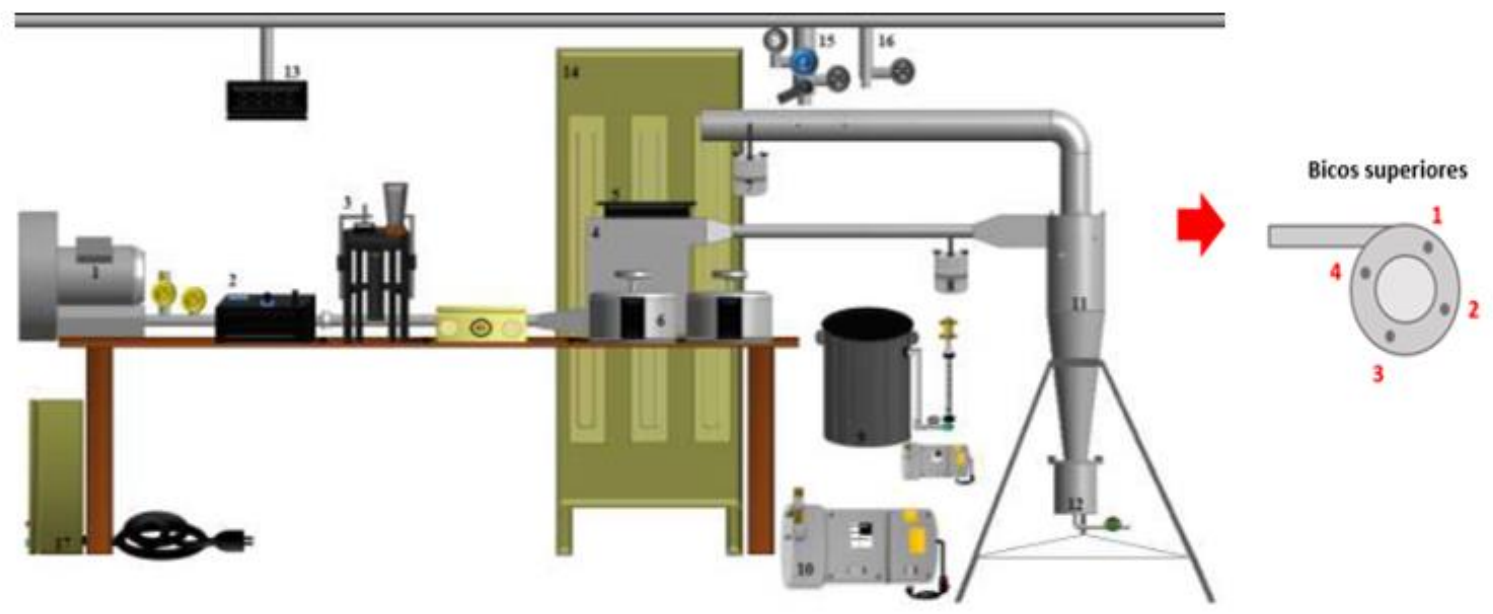

O funcionamento do sistema experimental consistia basicamente nas seguintes etapas: (A) O soprador era responsável por incorporar ao sistema um fluxo de ar, a uma vazão de $4,28 \mathrm{~m} / \mathrm{min}$, cujo controle era feito através das válvulas de escape e da coluna manométrica; (B) O fluxo gasoso seguia por uma seção retangular, em que as resistências elétricas foram mantidas desligadas para que o experimento ocorresse à temperatura ambiente; (C) A alimentação do material particulado, a uma vazão de $0,1062 \mathrm{~g} / \mathrm{min}$, era feita através do prato giratório com rotação de 30\%, no qual estava vinculado o variador de velocidade; (D) O fluxo gasoso contendo, então, as partículas de material era conduzido para a entrada do ciclone e para a sonda de amostragem à vazão de 800 1/h; (E) Ao passar pelo ciclone, a maior parte das partículas era coletada na caixa localizada embaixo do equipamento; (F) $\mathrm{O}$ gás tratado seguia pelo duto superior, onde era feita a amostragem de saída à $400 \mathrm{l} / \mathrm{h}$. Todos os experimentos foram realizados com $1 \mathrm{~h}$ de duração e para os ensaios a úmido foi utilizada uma vazão média de água de $350 \mathrm{l} / \mathrm{h}$.

A determinação da eficiência de coleta do equipamento (Equação 1) foi feita através de medições das quantidades de material particulado que entravam e saíam do equipamento. Tais valores eram determinados pelo processo de amostragem isocinética.

$$
\eta=\frac{C_{e}-C_{s}}{C_{e}}
$$

sendo,

$C_{e}$ : Concentração de material particulado na entrada do ciclone;

$C_{s}$ : Concentração de material particulado na saída do ciclone.

\section{RESULTADOS E DISCUSSÃO}

Nesta seção serão apresentados os resultados obtidos com a realização dos procedimentos experimentais apresentados na seção anterior. 


\subsection{Ensaios a Seco}

Os ensaios experimentais a seco foram realizados mantendo-se o sistema de pulverização de água desligado. Para garantir uma melhor confiabilidade dos resultados de eficiência do equipamento operando a seco, estes ensaios foram realizados em triplicata, como mostra a Tabela 1.

Tabela 1 - Resultados dos ensaios experimentais a seco.

\begin{tabular}{|c|c|}
\hline $\mathrm{N}^{\mathbf{o}}$ Ensaio & Eficiência $(\%)$ \\
\hline \hline 1 & 96,52 \\
\hline 2 & 82,83 \\
\hline 3 & 98,44 \\
\hline
\end{tabular}

Assim, através dos resultados de eficiência apresentados na Tabela 1, foi calculada uma média aritmética que resultou em $92,60 \%$. Ou seja, 7,40\% das partículas respiráveis de material particulado que entraram no ciclone operando a seco estavam presentes na corrente gasosa de saída.

Apesar da eficiência ter sido superior a 90\%, o que já é um resultado satisfatório, é de extrema importância que a operação do equipamento seja otimizada de forma a manter o melhor desempenho possível, garantindo assim as normas regulamentadas pelas legislações de controle ambiental. Neste sentido, foram iniciados os ensaios experimentais a úmido, cujos resultados serão exibidos na seção seguinte.

\subsection{Ensaios a Úmido}

Os ensaios experimentais a úmido foram realizados explorando todas as combinações possíveis de acionamento dos quatro bicos pulverizadores de água, localizados na parte superior do equipamento. A Tabela 2 apresenta os resultados obtidos para a eficiência do equipamento operando a úmido.

Tabela 2 - Resultados dos ensaios experimentais a úmido.

\begin{tabular}{|c|c|c|}
\hline $\mathrm{N}^{\mathbf{o}}$ Ensaio & Bicos Acionados & Eficiência (\%) \\
\hline \hline 1 & 1 & 95,87 \\
\hline 2 & 2 & 98,39 \\
\hline 3 & 3 & 98,59 \\
\hline 4 & 4 & 99,12 \\
\hline 5 & $1 ; 2$ & 99,10 \\
\hline 6 & $1 ; 3$ & 99,32 \\
\hline 7 & $1 ; 4$ & 97,69 \\
\hline 8 & $2 ; 3$ & 96,49 \\
\hline 9 & $2 ; 4$ & 95,29 \\
\hline 10 & $3 ; 4$ & 97,60 \\
\hline 11 & $1 ; 2 ; 3$ & 95,81 \\
\hline 12 & $1 ; 2 ; 4$ & 99,52 \\
\hline 13 & $1 ; 3 ; 4$ & 99,04 \\
\hline 14 & $2 ; 3 ; 4$ & 99,14 \\
\hline 15 & $1 ; 2 ; 3 ; 4$ & 99,90 \\
\hline
\end{tabular}


Através dos resultados obtidos e mostrados na Tabela 2, foi possível observar que o Ensaio 15 foi aquele que possibilitou a melhor eficiência de coleta $(99,90 \%)$ de material particulado respirável pelo equipamento operando a úmido. Este resultado pode ser justificado pelo fato de que, neste caso, todos os bicos pulverizadores estavam acionados, permitindo que uma maior quantidade de água fosse inserida no sistema e atuasse na coleta das partículas sólidas.

Desta forma, foi realizada a triplicata desta melhor condição de operação, a fim de garantir a confiabilidade dos resultados. A Tabela 3 apresenta os valores de eficiência do equipamento obtidos.

Tabela 3 - Resultados da triplicata da melhor condição de operação a úmido.

\begin{tabular}{|c|c|}
\hline Ensaio & Eficiência $(\%)$ \\
\hline \hline Tréplica 1 & 99,90 \\
\hline Tréplica 2 & 96,23 \\
\hline Tréplica 3 & 95,61 \\
\hline
\end{tabular}

Assim, através dos resultados de eficiência apresentados na Tabela 3, foi calculada uma média aritmética que resultou em $97,25 \%$. Ou seja, apenas $2,75 \%$ das partículas respiráveis de material particulado que entraram no ciclone estavam presentes na corrente gasosa de saída. Este resultado apresenta um aumento de 5,02\% na eficiência do equipamento em comparação com a operação a seco, o que é um valor expressivo e que proporciona uma melhora significativa na emissão dessas partículas poluentes na atmosfera.

\section{CONCLUSÃO}

A implementação de quatro bicos pulverizadores de água na parte superior do equipamento ciclone propiciou uma melhora significativa no desempenho de coleta de partículas respiráveis de carvão ativado presentes na corrente gasosa de análise. Esta mudança na forma de operação do equipamento possibilitou que a eficiência de coleta passasse de $92,60 \%$, com o equipamento operando a seco, para 97,25\%, com a inserção de água no sistema de operação.

Estes resultados significam que os objetivos deste trabalho foram atingidos, de forma que a eficiência do equipamento na coleta de partículas respiráveis foi otimizada, exibindo um aumento de $5,02 \%$. Além disso, foi possível concluir que a configuração que apresentou o melhor resultado de eficiência foi com os quatro bicos pulverizadores de água funcionando concomitantemente.

\section{REFERÊNCIAS}

ALMEIDA FILHO, F. Monitoramento e Controle de Emissão de Material Particulado em uma Fonte Estacionária. Dissertação de Mestrado, Universidade Federal de São Carlos, Departamento de Engenharia Química, São Carlos - SP, 2008.

ARANSIOLA, E. OJUMU, T.V.; OYEKOLA, O.O.; MADZIMBAMUTO, T.F.; IKHUOMOREGBE, D.I.O.. A review of current technology for biodiesel production: State of the art. Biomass and Bioenergy, v. 61, p. 276-297, 2014. 